on electronics, thermodynamics, power engineering or other specialist subjects. Support for Sir John's thesis came recently from the Institution of Chemical Engineers, which recommended that about 45 per cent of the teaching in a university should be devoted to pure science and mathematics. About an equal amount of time should be devoted to chemical engineering science and the remainder to other engineering science, report-writing and a foreign language.

Regard for the way basic science is being taught in Australian universities has been expressed by Prof. A. E. Alexander, professor of physical chemistry in the University of Sydney (Vestes, 3, No. 4; December 1960). Prof. Alexander's reflexions were mainly concerned with chemistry and stem largely from the low staff-student ratio. At the University of Sydney enrolments for chemistry in 1960 were 2,250 and were accommodated in eight parallel lecture courses, these being taken by three lecturers, two temporary lecturers, and three teaching Fellows. In Australia little sixth-form chemistry is taught in the schools and Prof. Alexander sighs for the British system so that the university could be spared an intolerable burden of mass production and be able to spend more time on teaching chemistry more appropriate to a university (see also Nature, 189, 444, 1961). For some time, however, the problem of large student numbers has to be faced and raises anew the questions posed by Sir Charles Morris-what kinds of basic science should be taught to applied scientists, how much of it should be taught in the schools and the university, and what teaching techniques the universities should adopt to deal with the inevitable large numbers. American universities have paid much more attention to what should be taught and how it should be taught, and both Britain and Australia have much to learn from them.

The time has surely come when such fundamental decisions should no longer be left to heads of departments or ad hoc committees composed of members whose main interests are in research. Should not each faculty of pure and applied science initiate major research projects, carried out by senior research Fellows, to determine the content of their courses, the way it should be taught, where the teaching should be done, how much should be left to the schools, how often revision should be carried out, and who should be consulted before revision takes place?

\title{
GOALS FOR SCIENCE IN THE UNITED STATES
}

$I^{\mathrm{N}}$ February 1960, General (formerly President) Eisenhower announced the appointment of a Commission on National Goals, and requested the members of this Commission to "develop a broad outline of co-ordinated national policies and programs" and to "set up a series of goals in various areas of national activity". The Commission's report, including sixteen essays written by selected individuals, was prepared and published in a volume entitled Goals for Americans.

For its essay on science, the Commission chose Dr. Warren Weaver, vice-president of the Alfred P. Sloan Foundation, who, aided by the advice and counsel of a number of distinguished American scientists, presented his contribution, which he called "A Great Age for Science".

As this article was written by one of America's leading scientists, and because of the number of requests for the material, it has been reprinted separately by the Foundation for special distribution *.

Of primary importance in Dr. Weaver's thesis is the need to recognize the importance of science teaching, and to reward teachers at all levels of the educational system. The fact that this need has been appreciated for some time, and is fairly self-evident, does not detract from its intrinsic importance. Concern is growing in the United States about the present-day neglect and disparagement of teachers,

* A Great Age for Science. By Warren Weaver. Pp. viii + 35 . (Reprinted from Goals for Americans.) (New York: Alfred P. Sloan Foundation, 1961.) which, long-existent at the more elementary levels, has now obtained a foothold in the universities. The university tradition of great scholar-teachers, dedicated to research, but eager and willing to teach younger students, is being undermined. Nowadays, scientists are being offered research posts with the added 'advantage' of very little teaching duty, and many full-time research scientists, working at the universities and receiving salaries from research contracts and grants, are, in the words of Dr. Weaver, "intellectual eunuchs, not at all involved in the propagation of their kind". Furthermore, the premium placed on particular types of scientists for certain industries (notably the defence industry) often leads to emergent Ph.D.s being offered research posts with salaries exceeding those of the professors supervising the theses. These trends are tending to denigrate the academic dignity and fundamental importance of teaching, and the trend should be reversed. It is Dr. Weaver's contention that there are no secondary roles so far as teaching and research are concerned; they should be equal partners.

Much space is devoted to a discussion of the position of science within the framework of society. That an enormous gap has opened up between the thinking of scientists and the views and attitudes of mind of creative artists and moralists is serious enough, but even more disastrous is the chasm which separates the scientist from the layman. Dr. Weaver quotes from The New Yorker of March 5, 1960: "These are hard times for the layman. He is no 
longer thought competent to work out his own opinions on many matters, even many that touch him intimately. His very survival has become the property of committees and the subject of learned arguments among specialists. He has little to say ... being largely ignorant of the information upon which plans for him are based".

Science is involved in many present-day social and political problems, and, in a democracy, these problems should be the concern of the citizens as well as the scientists. Further to this, science in the United States is now largely financed by Government agencies, which are under the ultimate control of the citizens. People ought not to have to subscribe to something they know nothing about.

These points make it imperative that individual citizens should have an improved understanding of what science is, and how it operates.

On more specific but nevertheless highly important goals, the question of financial support for science is discussed. Often there is not enough distinction made between research and development, and a cursory glance at budget statements of ' $R$ and D' (Research and Development) may give a misleading impression of the amount of support given to ' $R$ '. The figures indicate an enormous increase in the support of development, but the financial aid given to basic research has not kept pace. Although American defence commitments require enormous sums to be spent on development of missiles, rockets, etc., there is some criticism of the fundamental philosophy of State policy in this direction; military interservice rivalry and lack of understanding of military objectives lead to wasteful duplication of developmental projects, and 'crash programmes', undertaken more as a result of emotion than of reason ('space' is the perfect example), lead to a budget which is heavily overburdened on the develop. mental side. It is argued that, with the introduction of a little more common sense, the total annual national allotment for pure research, which at the moment is in the region of 8-900 million dollars, could easily and profitably be raised to 1,500 million dollars without increasing the overall research and development figures.

Attention is also directed to the part played by industry in promoting basic scientific research. Although most of the misguided, old-fashioned acrimony between academic and industrial scientists has now disappeared, only a very few of the best American industries have established a satisfactory liaison between the interests of the community and the interests of the individual. Other industries, although giving the appearance of following this pattern, do not, in fact, go far enough. Furthermore, although there has been great improvement, indus. tries do not, in general, give enough support to research and education in universities and colleges, or to development of particular fields of science on which they themselves depend.

'Crash programmes', which work on the false assumption that 2 billion dollars equal one solved cancer problem, often lack adequately trained and able personnel, and, most important of all, there has not been established a basic theory to work on. What is needed is a broad attack at the roots of a problem by means of reasoned, fundamental research rather than a phrenetically active but superficial attack, which reflects adversely on national maturity and prompts Dr. Weaver to ask himself, "What's the rush ?"

\section{ROTATION OF THE EARTH}

\section{The Rotation of the Earth}

A Geophysical Discussion. By Walter H. Munk and Gordon J. F. Macdonald. (Cambridge Monographs on Mechanics and Applied Mathematics.) Pp. xix +323. (Cambridge: At the University Press, 1960.) 70s. net.

7 THS masterly book very well conveys the intellectual excitement of present-day geophysical research. From an examination of the places from which ancient eclipses were observed, Halley pointed out that the Moon's motion in longitude was gradually accelerating. Some of the best mathematical minds in the eighteenth century concerned themselves with the complex problem of providing a complete theory of the motions of bodies of the solar system, and Laplace in 1787 finally decided that this acceleration of the Moon was due to a decrease in the eccentricity of the Earth's orbit arising from gravitational perturbations by the planets. However, about the middle of last century, J. C. Adams showed that Laplace had neglected certain terms and that, in fact, only half the acceleration of the Moon could be explained by purely gravitational causes.

Gradually it became evident that the discrepancy was due to a secular increase in the length of the day, that is, a slowing up of the Earth's rotation. The much more detailed knowledge of the Moon's longitude, acquired through astronomical measurements in the past few hundred years, has shown that in addition to this secular acceleration of the Moon's longitude there are irregular changes with a time scale similar to that of the geomagnetic secular variation (about 50 years). The work of numerous astronomers, culminating in the famous paper of Spencer Jones in 1939, showed that these irregular fluctuations are also due to the changes in the length of the day. Since the War the Earth's rotation has been timed accurately over much shorter periods still by quartz clocks and an annual term in the Earth's rotation discovered.

About a hundred years ago astronomical determ. inations of the latitude of observatories became accurate enough to detect that the Earth's axis of rotation is wobbling, with respect to the Earth, a few tens of feet during periods of twelve months and fourteen months. The extraordinary accuracy of astronomical measurements by which these various phenomena have been discovered should be a cause of wonder: the irregular changes in the length of the day, for example, are about one part in $10^{8}$. All these phenomena give very important information about the Earth, and Munk and Macdonald give a fascinating description of the analysis required to explain them. The secular deceleration of the Earth appears to result from the friction of the lunar oceanic tides; the irregular fluctuations in the length of the day from the turbulent motion 